Schrödinger equation is applied on this scale it eliminates the initial singularity in much the same way as its application to more conventional, smaller systems comes into its own at a point where classical physics breaks down. With this, the ultimate extension of the application of his equation to the Universe, Schrödinger would have been enthralled.

There is no space for me to examine all the papers in this volume, which includes contributions on boson condensation (Lewis), nonlinear optics (McConnell), unified field theories and particles (Hittmair, Salam), astronomy and astrophysics (Kibble, Seaton) and biology (Pauling, Perutz). In a sense that is best, for I must confess that I could not help being sympathetic to Pauling's somewhat egocentric contribution and in particular his view that Schrödinger's later work on biology, as recounted in What is Life?, was confused and misleading.

So much for Schrödinger the equation, what of Schrödinger the man? He remains elusive in these pages. Flamm explores his grandfather Boltzmann's considerable influence on Schrödinger. Despite the fact that they never met, Boltzmann was the spring of Schrödinger's interest in science: "His line of thought may be called my first love in science. No other has ever thus enraptured me or will ever do so again". Here are the roots of Schrödinger's attitudes and Boltzmann's work was often the point of departure for Schrödinger's own, including that on quantum mechanics. Their mutual admiration of Darwin was also the stimulus and support for Schrödinger's foray into biology, in which he sought, but more tentatively than Boltzmann, the physical basis of life. A cleare vision of the personality of de Valera, a thwarted academic who rechannelled his energies into politics, comes from McCrea's fascinating account of the emergence of the Dublin Institute and Schrödinger's involvement with it.

The scientific world directly and the general world indirectly has much to be grateful for in the life of Erwin Schrödinger. His was not so great a discovery that it would not have been made, perhaps within months, by others. Yet it fell to him to be first, and he had the power and confidence to explore many of its implications. That he left a rich legacy of calculational power and troublesome problems of the kind surveyed here is an epitaph he would have relished. These papers show that he reaches (as his later writings suggest he would like to think) from beyond the grave to tickle the intellect with the conundrums of quantum mechanics and to view the flourishing tree into which his acorn has grown.

P. W. Atkins is University Lecturer in Physical Chemistry at the University of Oxford, and a Fellow of Lincoln College, Oxford OX1 3DR, UK.

\section{Feasting with the Olympians}

\section{Walter Gratzer}

The Life It Brings: One Physicist's Beginnings. By Jeremy Bernstein. Ticknor \& Fields, New York: 1987. Pp. 171. \$16.95.

JEREMY Bernstein is a theoretical physicist, turned writer. He must, one surmises, have been a pretty good physicist for he broke bread with the likes of Yang, Lee and Gell-Mann; that he is a very good writer indeed is plain. His all-too-brief memoir began (like so much of the best science writing of recent years) as articles in the New Yorker and it is a wholly captivating read.

Bernstein conjures up for us his journey from a cultured middle-class Jewish home through one of the great New York high schools, cradle of Nobel Laureates (as for instance the St Elizabeth Gymnasium in Budapest once was in the intellectual heyday of Central Europe) and thence in 1947 to Harvard. There he slowly discovered his vocation by a process of trial and error that would be impossible in a British university and moved by way of pure mathematics into theoretical physics. He came under the influence first of Philipp Frank, student of Boltzmann and friend of Einstein, who embodied the European cultural tradition, and then of the remarkable indigenous school of younger physicists, led by the incomparable Julian Schwinger. It was Bernstein's first brush with genius. Schwinger was adulated and imitated by his students: to say "nucular", it seems, marked you as one of his followers. His lectures (like those of Feynman on the Western seaboard) were the stuff of academic legend (which certainly percolated into other Harvard Departments, such as Chemistry, as I well recall): they were delivered without notes, and the subject was developed anew at the blackboard, impromptu, mathematics and all.

Schwinger was a prodigy, who had taught himself physics and mathematics from the Encyclopaedia Britannica. Bernstein relates the story of the adolescent's encounter with I. I. Rabi at Columbia. Rabi had summoned his then student, the astronomer Lloyd Motz, to his office to discuss a paper. Motz asked if he might bring in someone who was waiting for him outside. "He brought in this kid in knee pants", Rabi recalled. "So I told him to sit down some place, and he sat down. Motz and I were arguing, and this kid pipes up and settles the argument. And I said, "Who the hell is this'?". Rabi eventually prised the lad away from City College, where he was failing courses in everything but physics, and with difficulty got him into Columbia.
Bernstein's later contact with the sinister world of the atom bomb and the dark contagion that seeped into physics from Los Alamos - - the physicists, in Oppenheimer's words, had known evil - was prefigured by his acquaintance with Wendell Furry. Furry had been a communist, but heroically refused to "take the Fifth" when arraigned before the House UnAmerican Activities Committee, and was broken, like Oppenheimer, on McCarthy's wheel. His was, Bernstein thought, a maimed personality. There is a poignant vignette of Furry, who had in happier times been regarded as an outstanding theoretician, sitting in on Schwinger's lectures, turning over the pages of Time magazine.

From Harvard Bernstein progressed to the Institute of Advanced Studies, presided over by Robert Oppenheimer. It was the high noon of the Institute: T.D. Lee, C.N. Yang and a host of other luminaries were in residence, and Bohr, Dirac and Pauli were frequent visitors. "We will have a ball", Oppenheimer had said to Bernstein before he arrived. Bernstein attached himself to a genial young physicist, Marvin Goldberger (now President of Caltech), and together they tackled some problems concerning the interaction of fundamental particles. One of their col-

"Pauli was noted for intolerance and intellectual thuggery ('So young', he was supposed to have snarled as a student brought his research seminar to a close, 'and already he has accomplished so little')."

leagues was Freeman Dyson, of whose prodigious mathematical powers Bernstein speaks with awe. His first experience came when Dyson wandered into the room as Bernstein and Goldberger were brooding over an integral equation of seemingly unfathomable complexity. Invited to examine it, Dyson owned that he was feeling especially strong that morning and offered to have a go at it. Twenty minutes later he returned with the solution - later rediscovered and published by two other workers, whose name it bears. "I cannot imagine", Bernstein writes, "what it must feel like to think with that rapidity and clarity in mathematics. Does everyone else appear to be going in slow motion? But I have learned enough mathematics to get pleasure and delight each time I see it happening".

When the end of Bernstein's contract approached, Oppenheimer proposed a period in Europe with Wolfgang Pauli, but a lecture given by Pauli at Columbia persuaded Bernstein that the great man's powers were in a state of terminal decline (and indeed he died soon after at the age of 58). Pauli was noted for intolerance and intellectual thuggery ("So young", he was supposed to have snarled as a student 


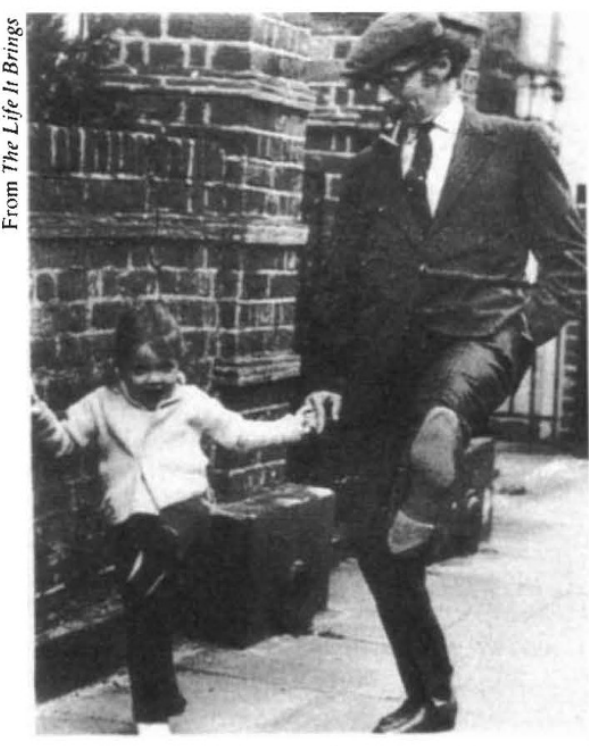

Jeremy Bernstein - pleasure in physics.

brought his research seminar to a close, "and already he has accomplished so little"). At the time he was preoccupied with a general theory of elementary particles, developed in association with Heisenberg, which was proving a delusion and which he was shortly to disown. He was confronted in the discussion that followed his talk by Niels Bohr, the most opaque and inarticulate of all the great illuminati. To capture the ascendant position facing the audience - the two lumbering mastodons circled the lecture bench, locked into orbit. Bohr had made the characteristically luminous criticism that the theory, though crazy, was not crazy enough. It lacked the quality of what is these days called a paradigm-shift, that it should outrage the common sense of the day (or, as Oscar Wilde had it, man can believe the impossible, but man can never believe the improbable). Pauli demurred: his theory was quite sufficiently crazy. It was not, said Bohr. Freeman Dyson compared the scene to the death of some noble animal.

Bernstein went instead to Paris, impelled by nothing more than a New Yorker article on eating in France. He took to it like a duck to orange sauce and, with a physicist friend, ate his way through Michelin, learned French and met for the first time Murray Gell-Mann, who had attended the same high school but had so far outstripped his contemporaries as to graduate from university when still more or less a child. Gell-Mann surfaced in the laboratory as Bernstein and his French patron, Louis Michel, were formulating the problem that was meant to engage Bernstein's attention for the next year Gell-Mann took it all in and left, only to reappear the next morning with the words - for he spoke flawless French "Messieurs, le problème est résolu". He had developed a general framework that would accommodate the problem and another of his own. Bernstein, awestruck, decided that an attempt must be made to understand the processes of thought that lay behind such casual miracles. $\mathrm{He}$ eventually conceded defeat, but he gives a transfixing description of the seemingly random explosions of perception that crackled around Gell-Mann's head. Genius, not for the first time, transcended analysis.

Bernstein expatiates on the pleasures of life in Paris in the early 1960 s and on the anfractuosities of French science; he found modern theoretical physics flowering improbably among thickets of ancient and impenetrable prejudice. His reminiscences stop at the point at which he regretfully leaves Paris and begins to forsake physics for writing, for the rest of his experience, he felt, had already been processed through the writer's mill and needed no further journey of rediscovery. His account of a brief career in physics is rich in anecdote of the great and the eccentric, and it conveys with great immediacy the pleasures and the rigours of intense intellectual labour. Theoretical physics, perhaps uniquely among the natural sciences, has preserved the traditional intellectual values. Its practitioners are the Olympians of the scientific community. Their research cannot be divided

"In chemistry, in biology, and most of all in 'big' physics, success now too often accompanies skills of a kind more often associated with the less fastidious type of advertising executive."

up and delegated; collaborations spring up, because many theoreticians like to test evolving ideas by debate, but in Dirac's words, "the really good ideas are had by one person". In chemistry, in biology, and most of all in "big" physics, success now too often accompanies skills of a kind more often associated with the less fastidious type of advertising executive.

Bernstein's years in physics were enviably fulfilling. W.B. Yeats wrote:

The intellect of man is forced to choose

Perfection of the life or of the work.

Bernstein's book is something of a negation of this austere maxim. His title is taken from a letter that Robert Oppenheimer wrote to his brother Frank, in which he recommended a career in physics for "the obvious excellences of the life it brings". Bernstein's celebration of these excellences is not to be missed.

Walter Gratzer is in the Medical Research Council Cell Biophysics Unit, King's College London (KQC), 26-29 Drury Lane, London $W C 2 B 5 R L, U K$

- On 22 May Princeton University Press will publish the first volume of The Collected Papers of Albert Einstein. The book, one of a projected total of about 40 , is entitled The Early Years, and covers the period 1879-1902.

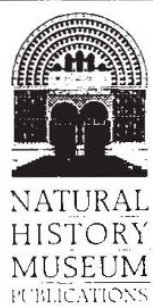

\section{Gemstones}

R. R. Harding \& C. M. Woodward

Full colour illustrations taken from the premier collection at the

Geological Museum, enhance this concise and authoritative guide to the subject.

64pp. Pbk. $0565010115 £ 4.95$

\section{Classic Minerals of Cornwall \& Devon}

P.G. Embrey \& R. F. Symes

Eighty specimens illustrated in full colour provide a spectacular record to many of the significant minerals to come from south-west England. $120 \mathrm{pp}, 80$ colour plates, 30 figs. Hbk. $0565009893 £ 9.95$

\section{The Alkaline Igneous Rocks \& Carbonatites of the World Part 1 North \& South America} A. R. Wooley

A series which will be of great interest to petrologists and geologists studying these economically important sources of many metals and non-metallic commodities. $224 \mathrm{pp}, \mathrm{A} 4$.

Hbk. $0565009710 £ \mathbf{4 0 . 0 0}$

\section{Seaweeds of the British Isles}

Vol. 3 Part 1

Fucophyceae (Phaeophyceae)

R. L. Fletcher

$320 \mathrm{pp}, 16$ plates.

Pbk. $0565009923 \mathbf{\$ 3 0 . 0 0}$

Vol. 4

Tribophyceae (Xanthophyceae) T.Christensen

48pp. Pbk. 056500980 X $£ 7.50$

Further volumes in this

comprehensive reference work on the marine algae of Great Britain and Ireland.

\section{Encyclopaedia of Ferns Vol. 1 \\ D. L. Jones}

A comprehensive survey giving details of habitat. classification and cultivation. Will be of interest to both botanists and horticulturalists. 460 pp. 250 colour photos.

$192 \mathrm{~b} / \mathrm{w}$ illustrations.

\section{Hbk. $0565010190 \mathbf{\$ 3 5 . 0 0}$}

Sales Department. Natural History Museum Publications. Cromwell Road. London SW7 5BD 